\title{
9. La vie sociale pour accompagner la personne âgée fragile
}

\author{
(C) Springer-Verlag France 2010
}

\section{1}

\author{
Les migrants âgés : une vieillesse piégée \\ M. Labidi \\ Café social, Paris, France
}

La vieillesse des migrants est frappée d'illégitimité. Elle surprend par son accomplissement en terre d'immigration et surtout par l'absence de sens, par son incongruité. L'âge de la retraite venu, ces anciens travailleurs n'ont pas tous repris le chemin du retour au pays. Bon nombre se partagent entre ici et là-bas. Leur vieillesse s'accomplit dans un couloir aérien. Ici, ils ont leurs repères et leurs habitudes de vie, voire ; là-bas, ils ont des attaches familiales et affectives. Ils ont besoin à la fois de leurs repères et de leurs attaches, et c'est certainement pour cette raison qu'ils vivent la douleur de n'avoir jamais trouvé leur place ici et peut-être de l'avoir perdue là-bas. Une position inconfortable qui génère le sentiment d'être de nulle part. Certains disent que l'endroit où ils sont finalement le mieux, c'est dans l'avion. Ainsi, vieillesse et immigration relèvent du paradoxe. Ce sont deux termes qui se renient. Jamais l'immigré ne devait se prévaloir d'un nouveau statut, notamment de retraité en terre d'immigration. Ce cas de figure n'a jamais été prévu, s'agissant d'accueillir provisoirement des personnes venues essentiellement pour le travail et qui devaient inéluctablement reprendre le chemin du retour dès la retraite. Ce retour était la condition même de leur émigration : ces migrants le portent comme un code génétique. Aujourd'hui, ces migrants retraités ont des petites retraites et vivent dans des conditions accablantes : logement, santé, isolement... Peu visibles dans les dispositifs gérontologiques, ils vieillissent hors champ dans une précarité insoupçonnée. Le Café social Belleville, ouvert en 2003, et le nouveau Café social Dejean, ouvert en avril 2008 tentent d'apporter des réponses concrètes à la prise en charge de ces anciens travailleurs laissés pour compte et oubliés. Le Café social est une approche en douceur de ce public discret et «sans demande ». Une équipe de travailleurs sociaux, d'animateurs, d'écoutants leur viennent en aide pour faciliter l'accès aux droits sociaux (retraite, santé, prestations, services...), démêler des situations administratives souvent complexes, proposer des activités et des animations (jardinage, sorties culturelles et touristiques...) pour sortir les vieux migrants de leur isolement, les écouter pour soulager leur détresse. Ce sont donc des femmes (la problématique des femmes migrantes vieillissantes est peu connue) et des hommes, des plus en plus nombreux, qui poussent la porte du Café social qui se laissent apprivoiser en douceur. Ce lieu d'accueil et de sociabilité a aujourd'hui sa place dans le paysage gérontologique. L'expérience commence à être connue et beaucoup de villes en France veulent s'en inspirer pour créer à leur tour des lieux destinés à accueillir les vieux migrants pour les aider et les accompagner dans la vieillesse.
9.2

Vie sociale et projets personnalisés

G. Zehnder

CADEI (culture, animation, découverte, éducation, insertion), activité de Pollen-Scop, Aubenas

La notion de projet, d'une manière générale, est un concept sur lequel les animateurs sociaux se penchent dès le début de leur formation, quelle qu'en soit le niveau. Les débutants l'attaqueront en se formant sur des projets d'activités. Les plus expérimentés, en fonction de leurs responsabilités, devront maîtriser la difficile articulation entre projet institutionnel, projet d'animation et de vie sociale, pédagogie de projet, projets personnalisés...

Tout d'abord : Qu'est-ce qu'un animateur social ? Ou plus précisément, dans quelle mesure a-t-il sa place dans l'accompagnement des personnes âgées fragiles ? Quel est son rôle?

De plus : Comment agit-il sur la vie sociale ? De quelle vie sociale parlons-nous ? Dans quelle mesure peut-on parler de soutien à la vie sociale si l'action de l'animateur ne s'appuie pas sur le projet de chaque personne, même, et surtout pour des activités de groupes?

Enfin, quels sont les freins à la mise en place d'un réel projet d'animation et de vie sociale articulé aux projets personnalisés ? Quels en sont les atouts à la fois pour les adultes âgés, mais également pour les personnes qui travaillent au quotidien avec elles?

D'une manière générale, quel que soit le public avec qui il travaille : l'animateur professionnel, formé à son métier est un travailleur social, spécialisé dans le loisir et la culture, et qui va utiliser ces médiateurs pour permettre à la personne de s'épanouir dans un groupe, d'agir sur son environnement, de faire des choix, de se projeter dans des actions qui ont du sens pour elle et pour le groupe dans lequel elle évolue.

Or, on observe que souvent, l'avance en âge s'accompagne d'un appauvrissement de la vie sociale des individus. Si l'état de santé de la personne nécessite une entrée en institution, médicale ou médicosociale, on remarque un abandon fréquent de sa propre vie sociale, qui va de pair avec sa liberté d'action, son indépendance. On peut même souvent constater une infantilisation plus ou moins marquée, à la fois par les familles, les connaissances, et parfois même, le personnel.

Cependant, si l'institution a pensé sont projet de vie sociale, si les équipes l'ont compris et y participent, l'entrée en institution pour une personne âgée fragile peut être l'occasion de retrouver une place dans un groupe et une vie sociale.

Cette intervention se construira autour de la nécessaire articulation entre projets personnalisés et projets de vie sociale sans laquelle la recherche d'une vie sociale pour la personne âgée fragile n'a pas de sens. 